http://jmscr.igmpublication.org/home/

ISSN (e)-2347-176x ISSN (p) 2455-0450

crossref DOI: https://dx.doi.org/10.18535/jmscr/v8i11.39

\title{
Prevalence of Peripheral Neuropathy in Chronic Kidney Disease
}

\author{
Authors \\ R Arun Raja ${ }^{1}$, Ashwinth ${ }^{2}$ \\ ${ }^{1}$ Post Graduate, Department of General Medicine, Rajah Muthiah Medical College and Hospital, Annamalai \\ University, Chidambaram, India - 608002 \\ ${ }^{2}$ AssistantProfessor, Department of General Medicine, Rajah Muthiah Medical College and Hospital, \\ Annamalai University, Chidambaram, India - 608002
}

\begin{abstract}
Introduction: Peripheral Neuropathy is a complication of chronic kidney disease. The study focuses the prevalence of peripheral neuropathy in Chronic Kidney disease patients admitted in our Hospital.

Methods: The study conducted in 50 patients affected with chronic kidney disease in Rajah Muthiah Medical College \& Hospital. The presence of peripheral neuropathy was assessed by nerve conduction study.

Results: Out of 50 patients, more than 31 patients with Chronic kidney disease grade 5 was suffered from peripheral neuropathy. Out of that 17 Patients have showed sensory and motor neuropathy, 8 patients show sensory neuropathy and 6 patients show motor neuropathy.

Conclusion: Distal Sensory Motor neuropathy is the most common type of peripheral neuropathy observed in CKD patients. Prevalence of PN is in high correlation with severity and duration of chronic kidney disease especially in CKD Grade 5.

Keywords: Chronic kidney disease, Peripheral Neuropathy, Nerve conduction study.
\end{abstract}

\section{Introduction}

Peripheral Neuropathy is a common complication of Chronic Kidney disease. Mostly Patients having symptoms of peripheral dysfunction would not complaint of it which have to be assessed or looked for. Since after Dialysis and transplantation, CKD patients Mortality had decreased But because of the long period of CKD, Patients are tend to development peripheral nerve dysfunction. Most common cause for peripheral neuropathy is chronic uremia. Neuropathy is mostly seen in Grade 5 CKD patients. Mostly Distal, Symmetrical and mixed sensory motor neuropathy are the commonest presentation in CKD patients most involving lower limb than upper limb. The rate of progression of neuropathy is proportional to the duration of CKD. Many other causes like serological abnormalities and biochemical abnormalities (Calcium, magnesium, phosphate, urea, creatinine) can cause peripheral neuropathy along with uremic state but can't be correlated well. The uremic neuropathy is reversed after hemodialysis which shows that neuropathy is due to the accumulation of dialyzabe metabolite.

\section{Aim}

The aim of the study is to evaluate the prevalence of peripheral neuropathy in CKD patients through Nerve Conduction Study. 


\section{Materials and Methods}

The prospective observational study was conducted at Rajah Muthiah Medical College, Chidambaram. The patients are included in this study with the clinical and biochemical parameters.

Inclusion Criteria: Patients aged above 18 yrs and Patient should be non diabetic.

Exclusion Criteria: Patients age less than 18yrs, diabetic patients, Autoimmune disorders, Chronic Alcoholics, Malignancy, Inherited peripheral neuropathy patients. After Selecting the Patients based on Inclusion ad Exclusion criteria, the presence of peripheral neuropathy is assessed through clinically and NCS.

\section{Results}

The total number of cases of this study is 50 patients. All 50 patients was assessed, Peripheral neuropathy was proved in 31 patients through clinically and Nerve conduction study.

From Table I, it shows the prevalence of peripheral neuropathy in relation to the Grades of CKD

Table 1: Prevalence of peripheral neuropathy in relation to the Grades of CKD

\begin{tabular}{|l|c|c|}
\hline $\begin{array}{l}\text { Duration of } \\
\text { CKD }\end{array}$ & $\begin{array}{c}\text { No of } \\
\text { Patients }\end{array}$ & $\begin{array}{c}\text { No of Patients with } \\
\text { Peripheral Neuropathy }\end{array}$ \\
\hline Grade 1 & 6 & $1(2 \%)$ \\
\hline Grade 2 & 6 & $3(6 \%)$ \\
\hline Grade 3 & 8 & $3(6 \%)$ \\
\hline Grade 4 & 14 & $10(20 \%)$ \\
\hline Grade 5 & 16 & $14(28 \%)$ \\
\hline Total & 50 & $31(62 \%)$ \\
\hline
\end{tabular}

31 Patients had peripheral neuropathy which is confirmed by Nerve conduction study. 17 patients showed both sensory motor neuropathy, 8 patients showed sensory neuropathy and 6 patients showed motor neuropathy. From the Table II, it reveals that the most common type of neuropathy in CKD patients is Sensory Motor Neuropathy. Out of these 31 patients only 12 patients had clinical evidence of peripheral neuropathy in the form of loss of ankle jerk, defective vibration sense, weakness of limbs and Numbness of limbs. Mostly lower limbs are affected more.
From Table II, Distribution of patients affected with the reference to type of peripheral neuropathy

Table 2: Distribution of patients affected with the reference to type of peripheral neuropathy

\begin{tabular}{|l|c|c|c|}
\hline $\begin{array}{l}\text { Sensory- } \\
\text { Motor PN }\end{array}$ & Sensory PN & Motor PN & Total \\
\hline $17(34 \%)$ & $8(16 \%)$ & $6(12 \%)$ & $31(62 \%)$ \\
\hline
\end{tabular}

\section{Discussion}

Peripheral Neuropathy is a common complication of CKD patients. These complication can affect both central and peripheral nervous system. Common CNS complications are Stroke, Cognitive dysfunction, Encephalopathy, Peripheral and Autonomic Neuropathies. These conditions have impact in both morbidity and mortality risk. Among the 50 patients, 31 patients showed evidence of peripheral neuropathy through nerve conduction study. The duration of CKD is varied from less than $1 \mathrm{yr}$ to more than 5yrs was assessed in this study showed that the prevalence of peripheral neuropathy is in relation with duration of CKD. Distal symmetrical sensory motor neuropathy is common type of peripheral neuropathy observed in this study and the incidence was 34\%. The Incidence of Sensory neuropathy was $16 \%$ and Motor neuropathy was 12\%. Truncal Neuropathy and Cranial Neuropathies was not assessed in our clinical study. $62 \%$ of our study population was observed with peripheral nerve dysfunction. Moreover, the results showed that prevalence of peripheral nerve dysfunction was observed more in subjects of long duration CKD patients.

\section{Conclusion}

The prevalence of peripheral neuropathy is $62 \%$ in patients suffering from CKD. Distal Symmetrical Sensory and Motor Neuropathy is the commonest type observed in this study. Loss of ankle jerk and vibration sensory loss are the most common clinical signs of peripheral neuropathy. The incidence of peripheral neuropathy is in high correlation with the severity and duration of chronic kidney disease. 


\section{JMSCR Vol||08||Issue||11||Page 229-231||November}

\section{References}

1. Kumar A, Prasad A, Dutta A, Roohi F. Study of nerve conduction velocity In tibial nerve of healthy male and female of different age groups. Int J Recent Sci Res 2015;6:4477-82

2. Harrison $\mathrm{T}$, Wiener $\mathrm{C}$, Brown $\mathrm{C}$, Hemnes A. Harrison's Principles ofInternal Medicine. 18 th $_{\text {ed. New }}$ York: McGraw-Hill Medical; 2012.

3. Raskin NH, Fishman RA. Neurological disorders in renal failure. $2^{\text {nd }}$ Part. N Engl J Med 1976;294:204.

4. Asbury AK, Victor M, Adams RD. Uremic polyneuropathy. Arch Neurol1963;8:41328.

5. Warrell D, Cox T, Firth J. Oxford Textbook of Medicine. Oxford: Oxford University Press; 2010.

6. Carp S. Peripheral Nerve Injury: An Anatomical and Physiological Approach for Physical Therapy Intervention. $1^{\text {st }}$ ed. Philadelphia, PA: F. A. Davis Company; 2015.

7. Bromberg M. Handbook of Peripheral Neuropathy. Hoboken: Informal Healthcare; 2005.

8. Comi G, Corbo M. Metabolic neuropathies. Curr Opin Neurol 1998; 11:523- 9.

9. Campese V, Romoff M, Lavitan D, Lane K, Massry S. Mechanisms of autonomic nervous system dysfunction in Uremia. J Urol 1982;127:405. 